\title{
Factors Affecting the Test Results of the National Students' Physical Health Standards in Colleges
}

\author{
Lei Luo \\ Hubei Business College \\ Wuhan, China 430079
}

\author{
Hao Xiong \\ Hubei Business College \\ Wuhan, China 430079
}

\begin{abstract}
Since the National Standards for Physical Health of Students (hereinafter referred to as the "Standards") have been implemented in all levels of schools across the country since 2007, they have achieved remarkable results, but as time goes by, the accuracy of the data is affected by various factors. Accurate test results can make a correct evaluation of students' physique and health. They not only provide a basis for students to formulate exercise plans and exercise, but also provide data support for schools and even regional education departments in formulating educational plans, programs or methods. This paper uses the literature data method, interview method, mathematical statistics method, logic analysis method, comparative analysis method to conduct research and analysis on the test work, and knows that the impact on the accuracy of the test data is mainly concentrated in four aspects: the participants' ideological cognition and test attitudes, selection of test processes and rational organization, accuracy and frequency maintenance of test instruments and natural environmental factors. And the paper puts forward reasonable suggestions for the impact of these four aspects: 1 . strengthen learning so that participants can correctly test the test; 2 . strengthen supervision to make the policies implemented; 3 . carefully organize and create a reasonable testing process; 4 . strictly summarize and make the test results available to the public.
\end{abstract} factor

Keywords—college; physical fitness; standard test; influence

\section{INTRODUCTION}

Since 2007, the National Student Physical Health Standard has achieved a lot of achievements since it was fully implemented at all levels of schools across the country. It has played an important role in promoting and motivating students to participate in physical exercise and to continuously enhance their physical fitness. With the increasing emphasis on the physique of students in the country, there are more and more researches on students' "standard" testing. The research direction has also shifted from the original simple data analysis to the study of students' physical problems. With the time going on, in order to pursue the students' passing rate and achieve the purpose of evaluation, the schools report the wrong data and false data, ignoring the accuracy of the data in the test process. Many researchers have noticed such situations and placed their research on the acquisition of test data and put forward their own opinions on such issues.
Accurate test results not only provide a basis for students to formulate exercise plans and exercise, but also provide data support for schools and even regional education departments in formulating educational plans, programs or methods. If we study factors which would have influences on the test data of Standard and analyze the reasons which cause it, we could offer solutions to solve them. As a result, it is a good way for us to prevent producing the useless data initially in order to ensure the accuracy of data and it would provide correct guidance for students. Thus, it could provide the correct reference for the school and other departments, and put the "Standard" test into practice.

\section{RESEARCH METHODS}

\section{A. Documentary Law}

Check and collect the literature and materials related to the "Standard" test of the college through cnki.net, read the books on "Interpretation of National Student Physical Health Standards", "Sport Physiology", "Sports Psychology", etc., and consult relevant policies of the national and educational departments, and provide theoretical basis for the thesis through detailed analysis and research of the data.

\section{B. Interview Method}

Conduct field visits to several universities in Hubei Province, interview sports department heads, physical education teachers, and students on specific issues, and keep in touch with some physical education teachers to understand the actual situation of the "Standard" test and listen to various suggestions to get valuable first-hand information.

\section{Mathematical Statistics}

The student's test data was statistically analyzed, mainly using Excel 2007 and SPSS14.0 software.

\section{Logic Analysis}

Using the knowledge and methods of logic, according to the data obtained by mathematical statistics, so the relevant issues are summarized, compared, analyzed and integrated. 


\section{E. Comparative Analysis}

Comparing the actual operation and requirements of college test with those of "Standard", this paper analyzes the influence of unreasonable means on test results.

\section{RESULTS AND ANALYSIS}

Since the trial of the Standard in 2002, a set of test project systems has been developed the principles of reliability, effectiveness, objectivity and standard. After more than ten years of practice testing, today's college physical fitness test project has removed the optional items, fixed to eight items: height, weight, lung capacity, sitting body flexion, 50 meters, standing long jump, sit-ups (female) or cited body up (male), 800 meters (female) or 1000 meters (male). These projects cover many aspects of body shape, function, physical fitness and athletic ability. The test data can objectively and effectively reflect the physical development, physical condition and exercise level of contemporary college students.

\section{A. The Effect of the Subject on the Results}

The subject being tested is the subject of the test, and all work should be carried out around the students. The behavior of the students and the performance in the test directly affect the accuracy of the test data. Students should pay attention to the test from the ideological point of view, actively participate in the exercise, and prepare for the test; actively and conscientiously, in the test process, and strive to achieve the best level of test results.

1) Ideological recognition: Because of the full implementation of the Standards, there are very few students who have not experienced the test in the high school stage. However, due to the pressure of exam-oriented education and further studies, there are not many students who really take the test seriously. After entering the university, some students have not turned the old concept of high school, and they think that the test is going through a game, so the test is not taken seriously. The specific performance is not to participate in the test or to find someone to take his place in the test; the students do not try hard in the test, or just measure the data; and the test is not standardized, wearing shoes, jeans for testing and other issues. In this way, the students did not play their own level during the test, resulting in the data being lower than the expected level, or simply the data of other students.

2) Preparation activities: Pre-sport preparation activities improve the functional level of the cardiovascular system and the respiratory system, thereby overcoming the physiological inertia of the internal organs and shortening the time course of entering the working state. And pre-sport preparation activities improve the excitability of the central nervous system and muscles, regulate the bad state of the body, speed up the brain reaction, coordinate with the participating sports centers, and prepare for the test. Therefore, preparing for activities before testing is conducive to the students' own level of play, so that the test results are closer to their maximum. However, in the actual test, most students did not understand the importance of preparation activities. They thought that the preparation activities cost their own physical strength, and they were unwilling to do preparatory activities or perfunctory things, resulting in low test data.

\section{B. The Tester's Impact on Test Results}

The tester is the organizer and implementer of the test, the team of testers who are skilled and responsible play the leading role of the tester to ensure the smooth progress of the test work.

1) Team composition: Most of the school's testers are led by the physical education department, supplemented by other departmental staff and students. The physical education staff and other department staff will have heavier teaching or tasks, and the test time is tight, so a considerable part of the test is done by the students. In this case, there will be cases where the tester and the subjects have a good relationship and are falsified and unsatisfied. The most common is to measure the position of the seat when the flexion does not require the leg to straighten, when the puller is up, the opponent is holding, the straight arm is not required. Not only does it seriously affect the accuracy of the data, but it also misleads the test requirements of other testers, resulting in confusion in the test order.

2) Work attitude: Nowadays, the annual testing work of each university has become normalized, and the testing time, participants, and testing procedures tend to be stable. The testers have accumulated rich experience after a long period of work. However, the long-term test is easy to make the tester psychologically slack, and the work attitude is not as serious as before. Then there are cases where the test policy is not strictly implemented, the work remuneration may be unsatisfactory, etc., and the tester does not take the test seriously, perfunctory things, etc. Specifically, the impersonation that occurs when the identity of the subjects is not strictly examined, the action requirements during the test are not strictly enforced, the manual test is not determined when the long jump is established, and the timing is not standardized.

\section{The Impact of Test Arrangements on Test Results}

The test arrangement refers to the test time, means, and organization form that the university arranges when conducting the test. Generally speaking, the test time is divided into physical education class, after-school time and a combination of the two; the means are manual test, instrument test and combination of the two; the organization form is centralized test and student self-test. When the manual test is concentrated in the physical education class, it will be easy to appear in a physical education class to measure all the items because of the tight test time. It is also easy to see the order of the test items because the number of testers is too large and the venue is limited. Nowadays, college students generally have less exercise, and measuring 
all the items at one time is too much exercise for them. If the test project is not arranged in an unreasonable manner, the student's test can't be completed. The final result is that the student walks away or simply gives up the test.

\section{Influence of Test Instruments on Test Results}

Test instruments are the tools of testing and are the guarantee of accurate data. Sensitive and accurate instruments not only get accurate data, but also reduce postworkload and improve students' test enthusiasm. However, in the actual test, the instrument factors have a great impact on the data, mainly in the following aspects: First, Due to insufficient funds, it is difficult to purchase new instruments and the working frequency of old instruments is too high, resulting in instrument wear and tear during long-term use. Second, the maintenance and maintenance personnel lack professional knowledge, and the instrument cannot be properly maintained and debugged after use. Third, excessive abuse by the user, rough treatment caused damage to the instrument. Fourth, the use of different manufacturers' instruments is not the same. Fifth, the instrument test method caused by the instrument manufacturer's constraints is different from the test method required by the Standard.

\section{E. Influence of Environmental Factors on Test Results}

Environmental factors mainly refer to temperature and climate. The temperature and climate change will have a significant impact on student's athletic ability, physical function and mood. Generally speaking, the deadline for the Ministry of Education to report data is December 31 of each year, but new students can enter the school every September, so most schools are scheduled to be in the second half of each year. In the second half of the year, in September and October, the temperature was high and the rainfall was not high. It is more suitable for outdoor sports. Students are also willing to participate in physical exercise. They can also play the maximum level of performance during the test and achieve higher results. In November and December, the temperature will turn cold, and the day is shorter, students are not willing to exercise outdoors, the test students are not easy to play the true level, so the test scores are relatively low.

\section{CONCLUSION AND SUGGESTIONS}

\section{A. Conclusion}

The test is rigorous, but there are many human factors in the test process, and the accuracy of the test data will inevitably be affected. There are following aspects: First, the participants' ideological cognition and test attitude; Second, the selection and reasonable organization of the test process; Third, the accuracy and frequency maintenance of the test instrument; Fourth, the natural environmental factors. Some factors can be avoided, some factors are inevitable, but the impact can be minimized.

\section{B. Suggestions}

1) To educate the participants so that they can treat the test correctly: Relevant departments should organize participants, including testers and subjects, organizers; leaders publicize and learn about the Standards content, exercise and other related knowledge and policies. Participants are aware of the contents of the Standards such as test items and weights, test methods, etc., from the ideological focus on testing, to enhance the level of awareness of the test, and thus actively and strictly participate in the test according to the test requirements.

2) To strengthen supervision so that the various policies of the standard can be implemented: After the data is reported, the test and check review work is actively carried out, the authenticity of the data is strictly examined and an accountability system is established, the executive leadership responsibility system is implemented, and the processing contents of the test results in the Standards are evaluated. So in this way schools should attach importance to testing and increase funding in testing. The testing work of Standard and students' physical health level are included in the evaluation system of colleges and universities, and counselors, parents and social personages are encouraged to pay attention to and participate in the test, so as to promote all aspects to pay attention to students' physical exercise through the test and improve students' enthusiasm for exercise.

3) To carefully organize to create a reasonable testing process: Before testing, thoroughly overhaul the test equipment, carefully plan the test, arrange the test at the appropriate temperature, and combine the centralized test with the dispersion test. The manual test is combined with the instrument test. In the test, the order of the test items should be optimized, the endurance project should be placed at the end, and the preparation time should be reserved; the subjects actively cooperate with the preparation activities to ensure that the test is performed as optimally as possible.

4) To seriously summarize and make the test results for the public: After the test data is reported, all colleges and universities should do a good summary, statistically investigate, and analyze the school test data, and do a good job of coping with the problems revealed by the school, and implement it into physical education and school sports. Actively guide students to actively participate in sports activities, thereby improving the physique of students. Students should actively receive feedback from the Student Physique Health Network, and develop a reasonable exercise plan and implementation with reference to exercise prescriptions. The data thus tested can be used by the public, and the purpose of the test can be truly implemented.

\section{REFERENCES}

[1] Editorial Board of "Interpretation of National Students' Physical Health Standards". Interpretation of National Students' Physical Health Standards [M]. Beijing: People's Education Press, 2007.

[2] Zhang Zongguo. Analysis of Subjective and Objective Factors Affecting the Test Results of National Students' Physical Health Standards [J]. Sports science, 2009, 29(9):86-91. (in Chinese)

[3] Pan Qidong. The Status Quo of the Test of National Student Physical Health Standards and the Analysis of Factors Affecting Test Results 
[J].Journal of Huizhou University (Natural Science Edition), 2009, 29(9):103-109. (in Chinese)

[4] Liu Jing, Meng Zhaoqin. Abandoning Data Exaggeration and Restoring Students' True Physique - Analysis of Students' Physique Testing Process and Non-standard Factors [J]. Journal of Mudanjiang University, 2009, 18(5):127-129. (in Chinese)

[5] Nie Tao, LI Qiuliang. Investigation and Analysis of the Status Quo of College Students' Physical Health and Development Countermeasures[J]. Journal of Guangzhou Physical Education Institute, 2016,36(5):5-9.(in Chinese) 